\title{
Two cases of ketosis-prone diabetes mellitus in Korean adolescents
}

\author{
Won Bin Hwang, MD, \\ Ji Hyun Kim, MD, PhD, \\ Sung Min Cho, MD, PhD
}

Department of Pediatrics, Dongguk University Ilsan Hospital, Goyang, Korea

Received: 30 January, 2019

Revised: 25 March, 2019

Accepted: 22 April, 2019

Address for correspondence:

Ji Hyun Kim, MD, PhD

Department of Pediatrics, Dongguk

University IIsan Hospital, 27

Dongguk-ro, Ilsandong-gu, Goyang

10326, Korea

Tel: +82-31-961-7190

Fax: +82-31-961-7188

E-mail:eogurdl@gmail.com

https://orcid.org/0000-0001-5489-

1169
In recent years, reports of diabetes mellitus (DM) cases that do not fit the traditional classification system have increased in prevalence. While insulin deficiency appears as type 1 DM (T1DM), the new type also has the clinical features of type 2 DM (T2DM); as such, this new type of DM is called ketosis-prone diabetes (KPD) and is correlated with findings of severe hyperglycemia and ketoacidosis. To provide a clear, clinical classification of DM, new classification systems are being studied. Among these, the $A \beta$ system demonstrates the highest sensitivity and specificity in predicting clinical features and prognosis. We report 2 cases of KPD in Korean pediatric patients. The first patient was referred while in a state of diabetic ketoacidosis (DKA) and was considered to have T1DM. However, their blood glucose was well-controlled even with small doses of insulin, and the treatment was able to be changed to metformin therapy. The second patient seemed to be a typical case of T2DM because of his obesity and strong family history. However, blood glucose was not well-controlled with a regular diet, and ketosis occurred. After performing a glucagon stimulation test, both patients showed different clinical features that were finally diagnosed as type A- $\beta+$ KPD. The rapid and accurate diagnosis of KPD can reduce the duration of inappropriate insulin use and improve patients' quality of life. Further, the treatment of KPD children should be individualized according to each patient's lifestyle to preventing recurrent DKA.

Keywords: Ketosis-prone diabetes, Child, Korean

\section{Introduction}

Diabetic ketoacidosis (DKA) is a typical clinical symptom of type 1 diabetes mellitus (T1DM) caused by the insulin deficiency that results from autoimmune destruction of islet $\beta$-cells. Type 2 diabetes mellitus (T2DM) is caused by insulin resistance and $\beta$-cell dysfunction and is generally not present with DKA. However, in recent years, there has been an increasing number of atypical cases of ketosis or ketoacidosis in patients thought to have T2DM, without these cases fitting the traditional classification system of the American Diabetes Association (ADA). ${ }^{1)}$ These atypical cases usually involve obese patients who have a family history of T2DM but who show severe hyperglycemia and ketoacidosis or ketosis, which is usually found in T1DM. This form of the disease has been labeled as ketosis-prone diabetes (KPD). New classification systems are being suggested to provide an updated, clear clinical classification of DM. Among these, the A $\beta$ system has the most sensitivity and specificity in predicting clinical features and prognosis. ${ }^{2)}$ The $\mathrm{A} \beta$ system divides DM into 4 subtypes: $\mathrm{A}+\beta-, \mathrm{A}-\beta-$, $A+\beta+$, and $A-\beta+$. These divisions depend upon the presence of autoimmune antibodies and the ability of $\beta$-cells to preserve insulin secretory function. ${ }^{1)}$ Although KPD is already known to be predominant in Africans and African-Americans, it has become increasingly reported worldwide in various races. ${ }^{2-4)}$ There are also several reports and studies on adult KPD cases in Korea, ${ }^{5-7)}$ but limited studies involving the pediatric population. ${ }^{8)}$ We herein report 2 cases of 
KPD in Korean pediatric patients.

\section{Case reports}

\section{Case 1}

\section{1) Clinical presentation}

The patient was a 12-year-old male with no underlying disease. Two months ago, polyuria and polydipsia were observed in this patient, as was a weight loss of $10 \mathrm{~kg}$ (about 15\% of the total body weight). The patient experienced intermittent abdominal pain with nausea and vomiting and therefore visited the Emergency Department. There was a family history of T2DM in his grandmother and his father's elder brother. There was no history of smoking, alcohol, or drug abuse. At the time of admission, his height was $173 \mathrm{~cm}(99 \%)$, weight was $58 \mathrm{~kg}(76 \%)$, and body mass index (BMI) was $19.38 \mathrm{~kg} / \mathrm{m}^{2}(50 \%)$ at Tanner stage I. The blood pressure was 119/90 mmHg (66\%/99\%), heart rate was 123 beats/min, respiratory rate was 19 times/min, body temperature was $36.5^{\circ} \mathrm{C}$, and the patient was mentally alert. On physical examination, there were no abnormalities other than a mildly dehydrated tongue. Similarly, the skin did not show acanthosis nigricans. The fundoscopic findings and neurologic examination results were also normal.

\section{2) Laboratory findings}

At the time of admission, the initial serum glucose level was $393 \mathrm{mg} / \mathrm{dL}$, ketone level was $6.6 \mathrm{mmol} / \mathrm{L}$, glycosylated hemoglobin $\left(\mathrm{HbA}_{\mathrm{lc}}\right)$ level was $12.4 \%$, fasting insulin level was $3.55 \mu \mathrm{U} / \mathrm{mL}$, and C-peptide level was $0.60 \mathrm{ng} / \mathrm{mL}$. Insulin antibodies, islet cell antibodies, and glutamic acid decarboxylase (GAD) antibodies were all negative. In the venous blood gas analysis, a $\mathrm{pH}$ of $7.179, \mathrm{pCO}_{2}$ concentration of $22.2 \mathrm{mmHg}$, and $\mathrm{HCO}_{3}{ }^{-}$concentration of $8.1 \mathrm{mmol} / \mathrm{L}$ were measured. Urinalysis showed the presence of protein $(+/-)$, glucose $(4+)$, and ketones $(3+)$. The chest X-ray and electrocardiogram suggested no abnormalities (Table 1).

\section{3) Treatment and clinical course}

The patient was admitted to the intensive care unit and diagnosed with DKA, subsequently beginning continuous intravenous insulin therapy. The symptoms improved and the patient's treatment was changed to subcutaneous insulin. The patient was then transferred to the general ward on the second day of admission. The dose of insulin glargine was $16 \mathrm{U}(0.28$ $\mathrm{U} / \mathrm{kg})$, while $8 \mathrm{U}(0.14 \mathrm{U} / \mathrm{kg})$ of insulin lispro was used before each meal. The blood glucose level remained stable with the maintenance of dietary habits, and the patient was discharged on the seventh day after admission. After discharge, the patient was followed up with in the outpatient department. The patient's total insulin was gradually reduced to $0.2 \mathrm{U} / \mathrm{kg}$ and his blood glucose levels have been controlled well, though he sometimes experiences hypoglycemic symptoms. The $\mathrm{HbA}_{\mathrm{lc}}$ level has been maintained at $5.5 \%$ to $6.1 \%$ and no recurrence of
DKA has occurred since the first DKA in 2016

4) Evolution of $\beta$-cell function

One year later, a glucagon stimulation test was performed in this patient in the outpatient clinic. The C-peptide level was measured at $1.72 \mathrm{ng} / \mathrm{mL}$ in the fasting state, $2.08 \mathrm{ng} / \mathrm{mL}$ at 5 minutes, and $2.27 \mathrm{ng} / \mathrm{mL}$ at 10 minutes after stimulation (Table 2).

\section{5) Conclusion}

The patient was first referred to DKA and was considered to have type $1 \mathrm{~B}$ DM during treatment. However, KPD was suspected because the blood glucose was well-controlled even with small doses of insulin, and the treatment was able to be

Table 1. Comparison of the clinical characteristics

\begin{tabular}{|c|c|c|}
\hline Characteristic & Case 1 & Case 2 \\
\hline Sex & Male & Male \\
\hline Age (yr) & 12 & 13 \\
\hline Body mass index $\left(\mathrm{kg} / \mathrm{m}^{2}\right)$ & 19.38 & 29.11 \\
\hline Family history of diabetes & Y & Y \\
\hline Newly diagnosed DM & Y & N \\
\hline Acanthosis nigricans & N & Y \\
\hline Fasting plasma glucose (mg/dL) & 393 & 474 \\
\hline $\mathrm{HbA}_{1 \mathrm{c}}(\%)$ & 12.4 & 11.6 \\
\hline Fasting C-peptide (ng/mL) & 0.60 & 0.91 \\
\hline Fasting insulin (mcU/mL) & 3.55 & 4.53 \\
\hline Insulin antibody & N & N \\
\hline Islet cell antibody & N & N \\
\hline GAD antibody & $\mathrm{N}$ & $\mathrm{N}$ \\
\hline Ketosis/ketoacidosis & Y & Y \\
\hline Ketone body (mmol/L) & 6.6 & 4.9 \\
\hline \multicolumn{3}{|l|}{ VBGA } \\
\hline $\mathrm{pH}$ & 7.179 & 7.305 \\
\hline $\mathrm{pCO}_{2}(\mathrm{mmHg})$ & 22.2 & 36.1 \\
\hline $\mathrm{HCO}_{3}^{-}(\mathrm{mmol} / \mathrm{L})$ & 8.1 & 17.6 \\
\hline Urine ketone & $3+$ & $3+$ \\
\hline Insulin requirement at discharge (U/kg/day) & 0.4 & 0.5 \\
\hline Duration of insulin therapy (yr) & 1 & Continuous \\
\hline Antidiabetic regimen at 12 months & Metformin & Insulin ${ }^{*}$ \\
\hline Recurrent DKA episodes & N & N \\
\hline KPD type & A- $\beta+$ type & A- $\beta+$ type \\
\hline \multicolumn{3}{|c|}{$\begin{array}{l}\text { DM, diabetes mellitus; } \mathrm{HbA}_{1 c} \text { glycosylated hemoglobin; GAD } \\
\text { glutamic acid decarboxylase; VBGA, venous blood gas analysis } \\
\text { DKA, diabetic ketoacidosis; KPD, ketosis-prone diabetes; } \mathrm{Y} \text {, yes; N } \\
\text { no. } \\
\text { "This patient possible to change to metformin treatment after } 1.5 \\
\text { years of hospitalization. }\end{array}$} \\
\hline
\end{tabular}

Table 2. Comparison of the results of the glucagon stimulation test

\begin{tabular}{lcc}
\hline Variable & Case 1 & Case 2 \\
\hline C-peptide at baseline $(\mathrm{ng} / \mathrm{mL})$ & 1.72 & 3.09 \\
C-peptide at 5 min after stimulation $(\mathrm{ng} / \mathrm{mL})$ & 2.08 & 4.43 \\
C-peptide at 10 min after stimulation $(\mathrm{ng} / \mathrm{mL})$ & 2.27 & 1.85 \\
\hline
\end{tabular}


changed to metformin therapy after discharge. We performed a glucagon stimulation test in the outpatient clinic, confirmed the function of the pancreatic cells as normal, and finally diagnosed the patient as having type A- $\beta+\mathrm{KPD}$. Because he considered the possibility of recurrence, the patient continued to follow up with us in the outpatient clinic regularly.

\section{Case 2}

\section{1) Clinical presentation}

The patient was a 13-year-old male who had been diagnosed with T2DM at another clinic 2 months before admission and was using an oral hypoglycemic agent (i.e., metformin 500 mg twice a day). Despite initiating this medication, however, the patient's usual preprandial blood glucose was not wellcontrolled, and a weight loss of 5 to $6 \mathrm{~kg}$ ( $6 \%$ of the total body weight) in a month as well as a symptom of nocturia were observed. After visiting our endocrine outpatient clinic, insulin glargine was started and increased up to $30 \mathrm{U}(0.4 \mathrm{U} / \mathrm{kg})$, but the blood glucose was maintained over $300 \mathrm{mg} / \mathrm{dL}$ continuously. The patient presented with nausea and lethargy on the day of admission to the emergency room. According to the patient's family history, the father, maternal grandmother, and uncle had all be diagnosed with T2DM. There was no history of smoking, alcohol, or drug abuse. At the time of admission, his height was $162.1 \mathrm{~cm}(75 \%)$, weight was $76.5 \mathrm{~kg}(99 \%)$, and BMI was 29.1 $\mathrm{kg} / \mathrm{m}^{2}$ (99\%). Severe acanthosis nigricans was identified on the neck, armpits, and axilla, while the fundoscopic findings and neurologic examination were normal. Recorded vital signs included a blood pressure of 119/78 mmHg (67\%/97\%), heart rate of 103 beats/min, respiratory rate of 20 times/min, and body temperature of $36.7^{\circ} \mathrm{C}$; additionally, the patient was mentally alert.

\section{2) Laboratory findings}

At the time of admission, initial serum glucose level was 474 $\mathrm{mg} / \mathrm{dL}$, ketone level was $4.9 \mathrm{mmol} / \mathrm{L}, \mathrm{HbA}_{1 \mathrm{c}}$ level was $11.6 \%$, fasting insulin level was $4.53 \mu \mathrm{U} / \mathrm{mL}$, and C-peptide level was $0.91 \mathrm{ng} / \mathrm{mL}$. Insulin antibodies, islet cell antibodies, and GAD antibodies were all negative. During the venous blood gas analysis, the following results were obtained: $\mathrm{pH}$ of $7.305, \mathrm{pCO}_{2}$ of $36.1 \mathrm{mmHg}$, and $\mathrm{HCO}_{3}{ }^{-}$of $17.6 \mathrm{mmol} / \mathrm{L}$. Urinalysis revealed findings of protein (-), glucose (4+), and ketones (3+). The chest $\mathrm{X}$-ray and electrocardiogram showed no abnormalities (Table 1).

\section{3) Treatment and clinical course}

The patient received fluid treatment for DKA and continuous intravenous insulin in the emergency room. The symptoms improved, and the patient moved to the general ward on the second day. The dose of insulin glargine was $30 \mathrm{U}(0.4 \mathrm{U} / \mathrm{kg})$, and $10(0.15 \mathrm{U} / \mathrm{kg})$ to $13 \mathrm{U}(0.17 \mathrm{U} / \mathrm{kg})$ of insulin lispro was given before each meal. The blood glucose level remained stable in the maintenance of dietary habits, and the patient was discharged on the 12th day after admission. In this patient, despite DM education, dietary and exercise therapy did not work well, and the insulin dose could not be reduced for one year after discharge. However, there was no subsequent recurrence of ketosis or DKA.

\section{4) Evolution of $\beta$-cell function}

Two weeks after the acute-phase DKA treatment, a glucagon stimulation test was performed in the outpatient clinic. C-peptide level was measured at $3.09 \mathrm{ng} / \mathrm{mL}$ in the fasting state, $4.43 \mathrm{ng} / \mathrm{mL}$ at 5 minutes, and $1.85 \mathrm{ng} / \mathrm{mL}$ at 10 minutes after stimulation (Table 2).

\section{5) Conclusion}

The patient seemed to represent a typical case of T2DM because of his obesity with severe acanthosis nigricans and strong family history of DM. However, KPD was ultimately suspected because of the poor blood glucose control and the occurrence of ketosis. The function of pancreatic cells was confirmed to be normal by the glucagon stimulation test, and the disease was finally diagnosed as type A- $\beta+$ KPD. After 1 year, regular exercise and dietary control were combined with regular DM education, and it was possible to change to metformin treatment after 1.5 years of hospitalization.

\section{Discussion}

Beginning in the 1960s, Dodu, Adadevoh, and others reported atypical cases of DM that did not fit the typical classification seen in African races. ${ }^{9,10)}$ Since the mid-1990s, similar cases have been reported not only in African populations, but also among Hispanic, Caucasian, European, Japanese, and Chinese patients. ${ }^{3,11,12)}$ Further, these cases had common features: patients were initially diagnosed with DM with ketosis or ketoacidosis, had no autoimmune antibodies, and subsequently improved to such an extent that insulin therapy was not needed. Maldonado et al. ${ }^{1)}$ classified these patients based on the presence of the $\beta$-cells' autoimmunity and the insulin secretion ability, subsequently introducing a new classification called the $A \beta$ classification that differed from the conventional ADA classification. Several related studies have been conducted in Korean adults. Kim et al. ${ }^{6}$ confirmed that approximately $40 \%$ of adults diagnosed initially with DM showing DKA in fact had KPD, while Seok et al. ${ }^{7)}$ reported that about $35 \%$ of patients diagnosed with KPD were autoantibody-free and had preserved $\beta$-cell function. As far as we know, a pediatric case in Korea introduced as T2DM with severe DKA is similar to case 2 in our report. $^{8)}$

KPD is one of the diabetic syndromes characterized by the dysfunction of $\beta$-cells and various clinical courses, yet the classical ADA classification scheme has limitations in explaining KPD. A variety of studies have attempted to provide a clear clinical classification of DM, and newer classification systems such as the modified ADA system, the BMI-based system, and the $A \beta$ system have been proposed. ${ }^{1)}$ Recent long-term studies have shown that the $A \beta$ system is the most 
sensitive and specific option among the new classification systems for predicting clinical features and prognosis. ${ }^{13)}$ The $\mathrm{A}+\beta$ - subtype is considered the same type as the existing ADA system's autoimmune T1DM, while the $\mathrm{A}+\beta+$ subtype is similar to latent autoimmune diabetes in adults, in which autoimmune antibodies exist and $\beta$-cell functions are slowly lost. In patients who have initially been diagnosed as DM with DKA, insulin treatment is necessary from the beginning. Most patients maintain long-term $\beta$-cell function but some show a gradual decrease in secretory capacity, and DKA may recur, requiring continuous follow-up. The A- $\beta+$ subtype accounts for most of the subtypes among KPD patients. ${ }^{1)}$ There is no autoimmune antibody, but the function of $\beta$-cells is temporarily reduced, leading to ketosis or ketoacidosis. It has been reported that exposure to glucotoxicity or lipotoxicity causes oxidative stress in $\beta$-cells, resulting in temporary dysfunction. These patients are generally obese and have a family history of T2DM, and within 6 months after the diagnosis of DKA, blood glucose is wellcontrolled and $50 \%$ of the affected patients have reached a level of remission that does not require insulin therapy. ${ }^{14,15)}$ Various factors that predict remission have been studied. C-peptide levels are known to be one of the predictors of recurrence within one year. Recently, the age at the onset of first episode of DKA was also reported to be important. ${ }^{16)}$ In a study of Korean adults, $75 \%$ of patients who were initially diagnosed with subtype A- $\beta+$ KPD no longer needed insulin therapy at one year after the first DKA episode. ${ }^{7)}$ Of these, $38 \%$ had relapsed within one year, however, requiring insulin therapy again, and the risk of recurrence was higher among those with an earlier age onset. ${ }^{16}$ )

The first step in KPD treatment, regardless of disease phenotype, is to correct the ketoacidosis. Aggressive fluid supply and intravenous insulin administration are needed and trigger factors and electrolyte imbalances must be corrected. After resolving the DKA, the next step is to convert intravenous insulin to subcutaneous insulin and maintain intensive insulin therapy for 24 hours before discharge. The initial evaluation of $\beta$-cell secretion through C-peptide levels and the presence of autoimmune antibodies should be confirmed. Afterward, the glucagon stimulation test should be retested at 2 to 3 weeks after DKA treatment to distinguish between transient desensitization of $\beta$-cells and permanent functional impairment. The glucagon stimulation test is the easiest way to confirm the function of $\beta$-cell secretion. C-peptide levels are measured at 0,5 , and 10 minutes after intravenous administration of $1 \mathrm{mg}$ of glucagon. If the fasting C-peptide level is greater than $1.0 \mathrm{ng} / \mathrm{mL}$ or the peak C-peptide level is greater than $1.5 \mathrm{ng} / \mathrm{mL}$, then the function of the $\beta$-cells is presumed to be preserved. ${ }^{1,2)}$

After discharge, the patient should be examined in the outpatient clinic every 2 weeks for the first 2 months and then observed every 2 to 3 months thereafter according to the blood glucose control status. During this time, the required average insulin need is about 1 to $1.2 \mathrm{U} / \mathrm{kg}$. If the patient maintains a fasting blood glucose level of less than $130 \mathrm{mg} / \mathrm{dL}$ for 2 weeks or experiences hypoglycemia, then the insulin dose may be reduced by $25 \%$ at each outpatient visit. When insulin is discontinued, patients with no autoimmune antibodies and who have recovered from the $\beta$-cell dysfunction can have their insulin treatments replaced with oral hypoglycemic agents such as metformin (500 mg twice a day), low-dose sulfonylurea $(1.25-2.5 \mathrm{mg} /$ day), or pioglitazone (30 mg/day). Importantly, patients with autoimmune antibodies are more likely to relapse, so careful follow-up is necessary. ${ }^{17)}$

In our first case, DKA developed early and appeared to be in the form of type 1B DM. However, throughout treatment, the extent of the remission made the insulin unnecessary, and the disease process observed was similar to that of T2DM. The second case involved a patient who was diagnosed with T2DM initially but whose disease appeared with ketosis and was not well-regulated by oral hypoglycemic agents. This case is similar to that one previously reported by Yu et al. ${ }^{8}$ However, we identified the insulin secretory function through the glucagon stimulation test. There was no recurrence of ketosis or DKA in this patient, but his dietary control was poor and exercise was not performed well. The progression of this case was similar to that of T1DM, requiring continuous insulin therapy. Overall, these case presentations did not fit the current typical DM classification. In these cases, the possibility of KPD should be considered. If KPD is suspected, a glucagon stimulation test should be performed to distinguish the type of KPD and appropriate treatment and follow-up. If KPD patients are misdiagnosed with T1DM, unnecessary insulin treatment can last for a long time, and side effects such as hypoglycemia may have a bad influence on the patient's quality of life. In contrast, If KPD patients are misdiagnosed with T2DM, hyperglycemia or DKA may be repeated when blood glucose control is poor. Although there are no long-term studies on the probability of relapse in children, an adult KPD study found that the younger the age, the higher the probability of relapse to the extent that insulin is needed. ${ }^{16)}$ Therefore, if KPD is suspected in children, especially if it is diagnosed as part of T2DM, education and blood glucose control are as necessary as they are for TIDM patients. KPD children and caregivers should measure their blood sugar and urine ketones as regularly as TIDM patients and routinely pay attention to DKA to prevent dangerous situations and unnecessary hospitalization.

\section{Conflict of interest}

No potential conflict of interest relevant to this article was reported.

\section{Ethical statement}

This study was approved by the Institutional Review Board (IRB) of Dongguk University Ilsan Hospital (approval number: DUIH 2019-01-013) and informed consent was waived by said IRB. 


\section{References}

1. Maldonado M, Hampe CS, Gaur LK, D'Amico S, Iyer D, Hammerle LP, et al. Ketosis-prone diabetes: dissection of a heterogeneous syndrome using an immunogenetic and beta-cell functional classification, prospective analysis, and clinical outcomes. J Clin Endocrinol Metab 2003;88:50908 .

2. Balasubramanyam A, Nalini R, Hampe CS, Maldonado M. Syndromes of ketosis-prone diabetes mellitus. Endocr Rev 2008;29:292-302.

3. Balasubramanyam A, Zern JW, Hyman DJ, Pavlik V. New profiles of diabetic ketoacidosis: type 1 vs type 2 diabetes and the effect of ethnicity. Arch Intern Med 1999;159:231722.

4. Mauvais-Jarvis F, Sobngwi E, Porcher R, Riveline JP, Kevorkian JP, Vaisse C, et al. Ketosis-prone type 2 diabetes in patients of sub-Saharan African origin: clinical pathophysiology and natural history of beta-cell dysfunction and insulin resistance. Diabetes 2004;53:645-53.

5. Yoon B, Kim G, Bae JH, Yun YJ, Lee YH, Lee BW, et al. A case of autoantibody-positive ketosis-prone diabetes mellitus. The Journal of Korean Diabetes 2016;17:60-6.

6. Kim MK, Lee SH, Kim JH, Lee JI, Kim JH, Jang EH, et al. Clinical characteristics of Korean patients with new-onset diabetes presenting with diabetic ketoacidosis. Diabetes Res Clin Pract 2009;85:e8-11.

7. Seok H, Jung CH, Kim SW, Lee MJ, Lee WJ, Kim JH, et al. Clinical characteristics and insulin independence of Koreans with new-onset type 2 diabetes presenting with diabetic ketoacidosis. Diabetes Metab Res Rev 2013;29:50713.
8. Yu JS, Jin HJ, Ko JT, Kang HS. A case of severe diabetic ketoacdosis in a child with type 2 diabetes. J Korean Soc Pediatr Endocrinol 2011;15:46-50

9. Dodu SR. Diabetes in the tropics. Br Med J 1967;2:747-50.

10. Adadevoh BK. "Temporary diabetes" in adult Nigerians. Trans R Soc Trop Med Hyg 1968;62:528-30.

11. Aizawa T, Katakura M, Taguchi N, Kobayashi H, Aoyagi E, Hashizume K, et al. Ketoacidosis-onset noninsulin dependent diabetes in Japanese subjects. Am J Med Sci 1995;310:198-201.

12. Tan KC, Mackay IR, Zimmet PZ, Hawkins BR, Lam KS. Metabolic and immunologic features of Chinese patients with atypical diabetes mellitus. Diabetes Care 2000;23:3358.

13. Balasubramanyam A, Garza G, Rodriguez L, Hampe CS, Gaur L, Lernmark A, et al. Accuracy and predictive value of classification schemes for ketosis-prone diabetes. Diabetes Care 2006;29:2575-9.

14. Weir GC, Laybutt DR, Kaneto H, Bonner-Weir S, Sharma A. Beta-cell adaptation and decompensation during the progression of diabetes. Diabetes 2001;50 Suppl 1:S154-9.

15. Eizirik DL, Korbutt GS, Hellerström C. Prolonged exposure of human pancreatic islets to high glucose concentrations in vitro impairs the beta-cell function. J Clin Invest 1992;90:1263-8.

16. Gaba R, Gambhire D, Uy N, Gonzalez EV, Iyer D, Hampe $\mathrm{CS}$, et al. Factors associated with early relapse to insulin dependence in unprovoked A- $\beta+$ ketosis-prone diabetes. J Diabetes Complications 2015;29:918-22.

17. Smiley D, Chandra P, Umpierrez GE. Update on diagnosis, pathogenesis and management of ketosis-prone Type 2 diabetes mellitus. Diabetes Manag (Lond) 2011;1:589-600. 